\title{
Outcomes of EUS-FNA in patients receiving antithrombotic therapy
}

\section{다)(앙}

\author{
Authors \\ Petcharee Polmanee ${ }^{1,2}$, Kazuo Hara', Nobumasa Mizuno', Susumu Hijioka', Takamichi Kuwahara', Nozomi Okuno', \\ Hiromichi Iwaya', Masahiro Tajika', Tsutomu Tanaka1, Makoto Ishihara', Yutaka Hirayama', Sachiyo Ohnishi' \\ Kazuhiro Toriyama', Patommatat Bhanthomkomol' ${ }^{1}$, Ayako Ito ${ }^{1}$, Naosuke Kuraoka ${ }^{1}$, Shinpei Matsumoto ${ }^{1}$, Yasumasa \\ Niwa ${ }^{1}$
}

Institutions

1 Department of Gastroenterology Aichi Cancer Center Hospital, Nagoya, Japan

2 Department of Internal Medicine, Bhumibol Adulyadej Hospital, Saimai, Bangkok, Thailand

submitted 7.12.2017

accepted after revision 21.6.2018

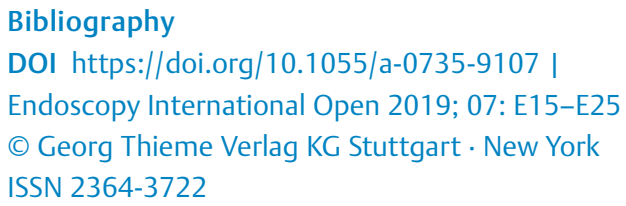

Corresponding author

Kazuo Hara, MD, Department of Gastroenterology, Aichi Cancer Center Hospital 1-1 Kanokoden, Chikusa-ku, Nagoya 464-8681, Japan

Phone: +81-52-764-2942

Fax: $+81-52-764-2963$

khara@aichi-cc.jp

\section{ABSTRACT}

Background and study aims To investigate bleeding risk and thromboembolic risk in patients receiving antithrombotic therapy who underwent endoscopic ultrasound-guided fine-needls aspiration (EUS-FNA).
Patients and methods $A$ single-center retrospective study of 908 consecutive patients undergoing EUS-FNA for pancreatic and non-pancreatic lesions patients between March 2013 and March 2017 was performed. Antithrombotic management was classified into three groups: continuous, discontinuation, and heparin replacement.

Results A total of 114 patients (12.6\%) were on antithrombotic drugs and 794 (84.6\%) were not. There were six cases of significant bleeding $(0.7 \%)$ four in the antithrombotic group $(0.4 \%)$ and two $(0.2 \%)$ in the non-antithrombotic group, (odds ratio, 9.59; $95 \%$ confidence interval, 2.12 $43.1 ; P=0.006)$. Of the four cases in the antithrombotic group, two were on continuous treatment, one was on discontinuation treatment and one was on heparin replacement. All cases of non-significant bleeding occurred in the non-antithrombotic group (3 peri-tumoral hematomas, 1 submucosal hematoma, and 1 intraluminal bleed). The sole thromboembolic event $(0.9 \%)$ was a cerebral infarction in the antithrombotic group in a patient on thienopyridine who switched to aspirin before the procedure.

Conclusions There was a slight increase in risk of bleeding in patients receiving antithrombotic therapy especially postoperative bleeding; however, there were no cases of severe bleeding was seen and only one case of cerebral infarction which occurred in a high-risk thromboembolic patients. We concluded that EUS-FNA in a safe procedure for patients on antithrombotics, even when antithrombotic therapy is not discontinued during EUS-FNA.

\section{Introduction}

Antithrombotic drugs, which are classified as either anticoagulants or antiplatelets, are widely prescribed for patients with a range of cardiovascular and thromboembolic conditions. These drugs increase bleeding risk during therapeutic endoscopic procedures [1 - 3], and risk of thromboembolic events increases when they are discontinued [4]. There are very few reports on the association between antithrombotic agents and endoscopic ultrasound-guided fine-needle aspiration (EUS-FNA) procedures. One prospective controlled study comparing EUSFNA and/or Trucut biopsy (TCB) in patients taking acetylsalicylic acid (ASA),non-steroidal anti-inflammatory drugs (NSAIDs) and low-molecular-weight heparin (LMWH) found that risk of bleeding in patients on antithrombotics was $33.3 \%$, compared to $3.7 \%$ in a control group [5]. A recent retrospective study from Japan included 746 patients, of whom 130 were receiving antithrombotic therapy (ASA or cilostazol), and recorded only 1 case of bleeding in the antithrombotic group [6]. 
In addition to risk of bleeding during EUS-FNA in patients taking antithrombotic drugs, discontinuation of these agents before or during procedures is significantly associated with an increase in thromboembolic events, such as stroke or pulmonary embolism. A recent retrospective study of 2,197 cases of ischemic stroke identified from hospital discharge records found that stroke ocurred in 114 patients (5.2\%) who had stopped taking warfarin or antiplatelet agents in the previous 60 days [7].

Several guidelines for antithrombotic management in endoscopy have been proposed, including guidelines from the British Society of Gastroenterology, the American Society of Gastrointestinal Endoscopy, the European Society of Gastrointestinal Endoscopy [8-10] and the Japan Gastroenterological Endoscopy Society (JGES) [11]. All guidelines have classified EUS-FNA as a high-risk procedure and peri-procedural management is based on antithrombotic groups and patient risk. The most recent Japanese guidelines (JGES) came after a consensus meeting in June 2011 where evidence-based guidelines on management of antithrombotic therapy in endoscopy incorporate use of oral antiplatelets and direct oral anticoagulant drugs (DOACs). These guidelines were published in Gastroenterological Endoscopy (Japanese) in 2012 and in Digestive Endoscopy in 2014 [12]. The guidelines classified patients as high and low bleeding risk after endoscopic procedures and investigated the factors associated with thromboembolism associated with withdrawal of antithrombotic therapy. However, since then, very few studies have been conducted. One retrospective study examined risk factors for early and delayed postoperative bleeding after endoscopic submucosal dissection (ESD) of gastric neoplasms. In patients who continued using low-dose aspirin, the bleeding risk of $9.5 \%$ [13] was comparable to other patients.

Our study sought to evaluate the outcome of EUS-FNA, especially bleeding and thromboembolic events, in patients receiving antithrombotic therapy, following revision of the 2011 JGES guidelines. We aimed to investigate how the relative risks of bleeding and ischemia can be balanced after discontinuation of antithrombotic drugs.

\section{Patients and methods}

\section{Patients}

The records of 1,244 patients who were scheduled to undergo FNA between March 2013 and March 2017 at Aichi Cancer Center Hospital were reviewed and data from 908 patients who met the inclusion criteria were analyzed. Data were collected from a computerized database of all patients who registered and had provided written informed consent for EUS-FNA. EUS-FNA procedures were performed by gastroenterologists or under the supervision of a senior gastroenterologist who had been performing EUS procedures for more than 10 years. A total of 114 patients had been taking antithrombotic drugs, such as ASA, clopidogrel, cilostazol, dipyridamole, ticlopidine, warfarin, another antiplatelet agent, or DOACs, for more than 1 month ( Fig.1). We excluded patients who had undergone an invasive high-risk endoscopic procedure in the month prior to EUS-

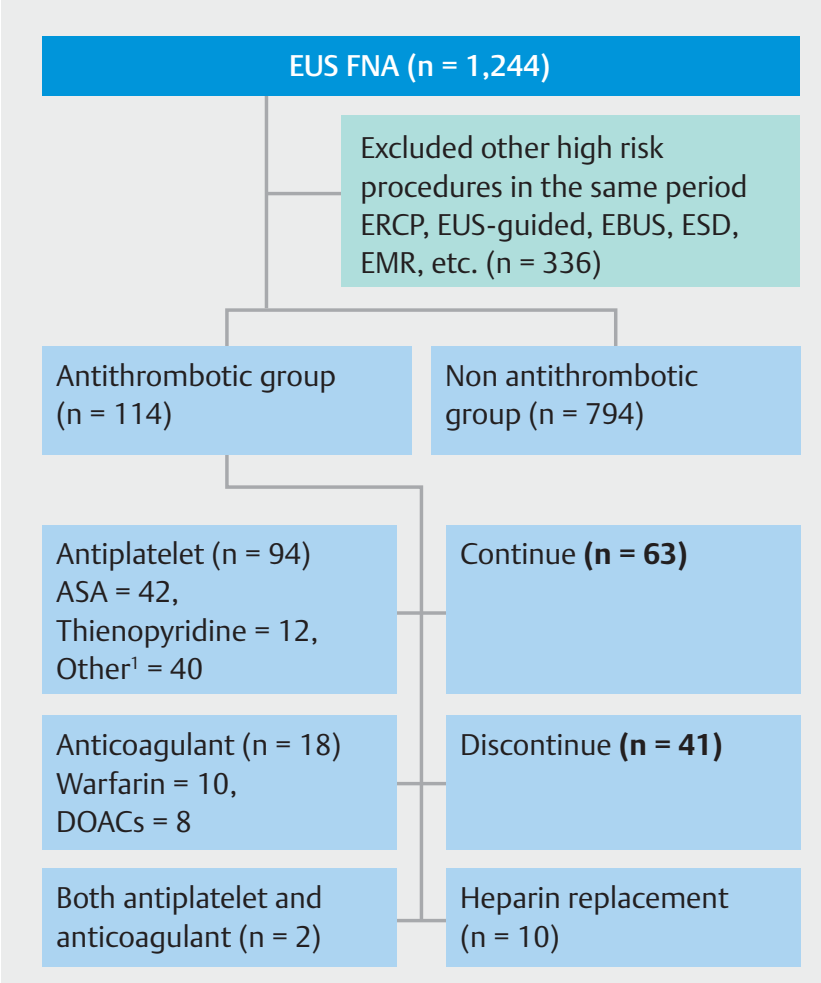

- Fig. 1 Flow diagram of patients who underwent endoscopic ultrasound-guided fine needle aspiration and received antithrombotic therapy. ERCP, endoscopic retrograde cholangiopancreatography; EBUS, endobronchial ultrasound bronchoscopy; EUSguided, endoscopic ultrasound-guided; ESD, endoscopic submucosal dissection; EMR, endoscopic mucosal resection; ASA, acetylsalicylic acid; DOACs, direct oral anticoagulants

${ }^{1}$ Other antiplatelets (10 ASA + thienopyridines, 10 prostaglandin, 7 ASA with thienopyridines + eicosapentane, 6 eicosapentane, 3 ASA or thienopyridines + prostaglandin, 2 cilostazol, 2 saprogrelate),

FNA (endoscopic retrograde cholangiopancreatography, EUSguided drainage, endobronchial ultrasound endoscopy, endoscopic submucosal dissection, endoscopic mucosal resection, EUS-guided cystic analysis, etc.), because adverse events (AEs) usually occur within this period [14]. We also excluded patients at high risk of bleeding due to bleeding disorders such as aplastic anemia, idiopathic thrombocytopenia, thrombocytopenia, and hemophilia, as well as those with coagulopathy or platelet dysfunction from end-stage renal disease requiring dialysis, and those with decompensated cirrhosis.

Before any decisions were made on administration of antithrombotic drugs, cases were discussed with the primary physician before the procedure and the coagulogram (international normalized ratio [INR] $\geq 1.5)$ and platelet number $(>80,000 /$ $\mathrm{mL}$ ) were normalized. All patients on antithrombotic drugs were managed according to the JGES guidelines depending on the type of drug and thromboembolic risks [11,12]. EUS-FNA was considered to be a high-risk procedure. Patients in the antithrombotic group were further classified into three subgroups: 1) continuous treatment group with patients receiving 
monotherapy of ASA/cilostazol and in whom non-aspirin nonthienopyridines antiplatelets were discontinued the day of the procedure; 2) a discontinuous treatment group, which included some patients on warfarin or DOACs who were at high risk of bleeding but low risk of thromboembolism plus the thienopyridines group (e.g. clopidogrel was discontinued 5-7 days before the procedure and ASA/cilostazol was continued or patients switched to ASA if monotherapy); and 3) a heparin replacement group in which warfarin was suspended and replaced with unfractionated intravenous or subcutaneous heparin 3 to 5 days before endoscopy and then heparin suspended at least 3 to 6 hours before endoscopy. Patients in this group who were taking warfarin or DOAC were considered at high risk of thromboembolism. DOACs should be suspended 24 to 48 hours before the procedure, and heparin replacement introduced 12 hours later. After temporary withdrawal of antithrombotics, the same regimen was reestablished as soon as hemostasis was confirmed. Generally, administration of aspirin, non aspirin antiplatelets, warfarin and heparin should be resumed after the procedure, with warfarin or DOAC resumed when oral intake which re-established.

The study was approved by the institutional review board of Aichi Cancer Center Hospital (approval no. 2016-1-363).

\section{Methods}

EUS-FNA was performed with the patient in the left lateral position under conscious sedation using intravenous midazolam (5 $\mathrm{mg}$ ) and pethidine (25-100 mg). An Aloka Prosound Alpha 10 or EU-ME2 compact ultrasound processor was used with a GFUCT 240 or GF-UCT 260 linear array echoendoscope, (Olympus Medical Systems Corp., Tokyo, Japan). A 19-G, 20-G, 22-G, or 25-G needle was used to perform EUS-FNA after target lesion confirmation. During and after FNA, color Doppler imaging was performed to rule out intervening blood vessels and signs of bleeding (new hypoechoic or hyperechoic areas) [15]. Intraluminal bleeding was defined as blood loss from the puncture site. Negative pressure was used with or without a $20-\mathrm{mL}$ syringe in cases with an increased bleeding risk, such as hypervascular tumors. Patient characteristics recorded included the maximal diameter of lesions, site of lesions, route of puncture, needle size, the number of FNA passes, underlying diseases, age, sex, lab chemistry, indication for antithrombotic drugs, other predictive risk factors for bleeding, and length of hospital stay. After the procedure patients' clinical events (especially hematemesis, melena, and thromboembolic events), vital signs, lab chemistry hemoglobin, ultrasound, computed tomography imaging (or other imaging) were recorded within 2 to 4 weeks.

We focused on outcomes in terms of bleeding and thromboembolic events, especially stroke and pulmonary emboli. Bleeding events and severity grading were defined according to the definitions of the American Society for Gastrointestinal Endoscopy [14]. Significant bleeding events were defined as follows: $>2 \mathrm{~g} / \mathrm{dL}$ drop in hemoglobin level compared with baseline and/or a history of melena, hematemesis, hematochezia with no other cause of upper gastrointestinal bleeding, or evidence of intra-abdominal bleeding on imaging (ultrasono- graphic imaging reveal new hyper or hypo-echoic lesions or bleeding evidence from computed tomography (CT) imaging. In addition, severe bleeding was defined as cases where a transfusion and/or hemostasis by endoscopic procedure, radiological intervention, or surgery was required. Bleeding events relating to the procedure (classified as intraoperative bleeding) were defined as events occurring during the procedure and up to 1 hour after the procedure. Postoperative bleeding was defined as bleeding detected within 14 days post-procedure and delayed bleeding after 14 days [14]. Adverse events (AEs) were graded as follow: Grade 1 mild (needs medication); Grade 2 moderate (needs ventilation, intervention, or surgery and prolonged hospital stay of 4-10 days); Grade 3, severe (prolonged hospital stay of $>10$ days, intensive care unit stay of $>1$ day, needs surgery, or causes disability); and Grade 4 fatal [14].

\section{Statistical analysis}

Categorical variables were analyzed using Fisher's exact test or the Chi-square $\mathrm{X}^{2}$ test. The independent sample $t$-test was used to compare continuous variables. Odds ratios (ORs) and $95 \%$ confidence intervals $(95 \% \mathrm{Cl})$ were calculated to evaluate predictors of complications. Two-tailed $P$ values less than 0.05 were considered statistically significant. All calculations were performed using SPSS version 20 (IBM Corporation, Armonk, New York, United States).

\section{Results}

Of the 908 patients undergoing EUS-FNA, 114 (12.6\%) were receiving antithrombotic therapy while 794 (84.6\%) were not, and management of antithrombotic agents during the EUS procedure is shown in Fig. 1. Baseline demographic data are shown in $>$ Table 1. Median age of patients in the antithrombotic group was 72 years (range, 64-80 years) and most were male (76 males, 38 females). The non-antithrombotic group had a mean age of 63 years (range, 52-74 years) with 439 males and 355 females.

Of the 114 patients taking antithrombotics, 42 were on ASA, 10 on clopidogrel, 2 on ticlopidine, 10 on warfarin, 40 on other antiplatelets (10 ASA + thienopyridines, 10 prostaglandin, 7 ASA with thienopyridines + eicosapentane, 6 eicosapentane, 3 ASA or thienopyridines + prostaglandin, 2 cilostazol, 2 saprogrelate), 8 on DOACs, and 2 on both antiplatelets and anticoagulants. Patients were divided into 3 groups based on pharmaceutical management: 1$)$ continuation $(n=63)$; 2 ) discontinuation $(n=41) ; 3)$ heparin replacement $(n=10)$ ( Fig. 1$)$. Age, male sex, comorbidity, hemoglobin before and after the procedure, and INR were significantly different in the two groups $(P<$ 0.05 ); however, body mass index, platelet count, and length of hospital stay were not ( $\triangleright$ Table $\mathbf{1})$.

Lesion and procedure characteristics were not significantly different in the two groups. The most common lesion puncture site was the pancreas $(n=513,56.5 \%)$, which included 381 pancreatic cancers (42\%). The other 132 pancreatic lesions (14.5\%) comprised 53 pancreatic neuroendocrine tumors (PNETs), 30 cases of chronic pancreatitis and benign masses, 18 of autoimmune pancreatitis, 21 macrocystis lesions (intraductal papillary 
- Table 1 Baseline characteristics of patients.

\begin{tabular}{|c|c|c|c|}
\hline Patients data & $\begin{array}{l}\text { ATD group }(n=114) \\
\text { Mean } \pm \text { SD }\end{array}$ & $\begin{array}{l}\text { Non ATD group }(n=794) \\
\text { Mean } \pm \text { SD }\end{array}$ & $P$ value ${ }^{2}$ \\
\hline Age & $72(64-80)$ & $63(52-74)$ & $<0.001^{1}$ \\
\hline Male/Female & $76 / 38$ & $439 / 355$ & $0.022^{1}$ \\
\hline $\operatorname{BMI}\left(\mathrm{kg} / \mathrm{m}^{2}\right)$ & $21.62 \pm 2.84$ & $21.82 \pm 3.48$ & 0.557 \\
\hline Underlying disease $^{1}$ & & & $<0.001^{1}$ \\
\hline DM & 38 & 347 & \\
\hline HT & 8 & 81 & \\
\hline DM, HT & 28 & 98 & \\
\hline ESRD without hemodialysis & 4 & 8 & \\
\hline Decompensated Cirrhosis & 1 & 9 & \\
\hline CAD & 21 & 1 & \\
\hline CVA & 4 & - & \\
\hline $\mathrm{AF}$ & 4 & - & \\
\hline DVT & 3 & - & \\
\hline PVD & 2 & - & \\
\hline PE & 1 & - & \\
\hline Platelet count $\left(\times 10^{4} / \mathrm{ul}\right)$ & $21.87 \pm 7.05$ & $23.79 \pm 12.34$ & 0.105 \\
\hline INR & $1.15 \pm 0.15$ & $1.05 \pm 0.09$ & $0.007^{1}$ \\
\hline Hemoglobin before FNA ( $\mathrm{g} / \mathrm{dl})$ & $12.53 \pm 1.79$ & $13.14 \pm 1.72$ & $0.001^{1}$ \\
\hline Hemoglobin after FNA (g/dl) & $11.90 \pm 1.66$ & $12.47 \pm 1.68$ & $0.001^{1}$ \\
\hline Length of hospital stay & $5.52 \pm 7.76$ & $4.30 \pm 6.98$ & 0.088 \\
\hline \multicolumn{4}{|c|}{$\begin{array}{l}\text { DM, diabetes mellitus; } \mathrm{HT} \text {, hypertension; CAD, coronary arterial disease; ESRD, End-stage renal disease; CVA, cerebrovascular disease; PE, pulmonary embolism; } \\
\text { PVD, peripheral vascular disease; DVT, deep vein thrombosis; Hb, hemoglobin; ATD, antithrombotic drugs; SD, standard deviation; FNA, fine needle aspiration } \\
1 \text { Important underlying disease-related antithrombotic treatment. Some patients had multiple underlying diseases } \\
{ }^{2} \text { Statistically significant }(P<0.05)\end{array}$} \\
\hline
\end{tabular}

mucinous neoplasms, and solid pseudopapillary tumors), and 10 microcystic lesions (PNETs, serous cystic neoplasms). Nonpancreatic lesions included 164 lymph node lesions, 88 hepatobiliary tract lesions, and 143 lesions of the non-gastrointestinal tract. Maximal diameter, puncture route, number of EUS passes, suction technique, cystic nature, presence of ascites, and lesion vascularity were not statistically significant between the two groups ( $>$ Table 2 ).

Significant bleeding occurred in six patients $(0.7 \%)$; four in the antithrombotic group $(0.4 \%)$ and two in the non-antithrombotic group $(0.2 \%)$ (univariate OR, 9.59; $95 \% \mathrm{Cl}, 2.12$ 43.1; $P=0.006$; multivariate $\mathrm{OR}, 14.4 ; 95 \% \mathrm{Cl}, 2.6-79.54 ; P=$ 0.002 ) ( $\triangleright$ Table 4 ). All cases of bleeding cases occurred postoperation and all were confirmed by hemoglobin drops and ultrasound or CT. None of these patients required blood transfusion and were treated conservatively until clinical improvement and bleeding stoppage. The four cases of bleeding $(3.4 \%, 4 /$ 114 ) in the antithrombotic group ( 1 on ASA, 1 on ASA/clopidogrel, 1 on another oral antiplatelet, and 1 on warfarin) occurred in the continuation $(3.2 \%, 2 / 63)$, discontinuation $(2.4 \%, 1 / 41)$ and heparin subgroups $(10 \%, 1 / 10)$ ( $\triangleright$ Table 3$)$.

There were five cases of non-significant bleeding ( $\mathrm{Hb}$ drop $\leq 2 \mathrm{~g} / \mathrm{dL}$ ) in the non-antithrombotic group. Most were intraoperative bleeds confirmed by Doppler ultrasound, Three cases had enhanced echogenicity of the peritumoral lesions, one had a submucosal hematoma, elevated gastric mucosa at the puncture site, and a hypoechoic lesion in the gastric mucosal layer, and one was bleeding from the puncture site accompanied by a spontaneous self-limiting bleed. There was no need for endoscopic or surgical intervention. The total number of bleeding events was 11 , four in the antithrombotic group, and seven in the non-antithrombotic group. The difference in bleeding rates between the antithrombotic and non-antithrombotic groups was significantly different on univariate $(P=$ $0.039)$ and multivariate analysis $(P=0.027)$ ( $\triangleright$ Table 4$)$.

Other adverse events recorded included one cerebral infarction, one case of acute pancreatitis, 11 postoperative fever (infection unknown source), and one case of hypotension. The patient who developed the acute cerebral infarction in the antith- 
- Table 2 Baseline characteristic of procedure and final diagnosis.

\begin{tabular}{|c|c|c|c|c|}
\hline & $\begin{array}{l}\text { ATD group } \\
n=114(\%)\end{array}$ & $\begin{array}{l}\text { Non ATD group } \\
n=794(\%)\end{array}$ & $\begin{array}{l}\text { Total } \\
n=908\end{array}$ & $P$ value \\
\hline Diagnosis & 114 & 794 & 908 & 0.280 \\
\hline Pancreatic lesions & $73(64.0)$ & $440(55.4)$ & $513(56.5)$ & \\
\hline Pancreatic CA & $57(50)$ & $324(40.8)$ & $381(42)$ & \\
\hline Other pancreatic disease & $16(14.0)$ & $116(14.6)$ & $132(14.5)$ & \\
\hline - AIP & 5 & 13 & 18 & \\
\hline - Chronic pancreatitis/benign mass & 3 & 27 & 30 & \\
\hline - PNETS & 3 & 50 & 53 & \\
\hline - IPMC/SPN & 5 & 16 & 21 & \\
\hline - Micro-cystic lesion (SCA, PNETs) & - & 10 & 10 & \\
\hline Hepatobiliary tract disease & $11(9.6)$ & $77(9.7)$ & $88(9.7)$ & \\
\hline Liver metastasis & 4 & 25 & 29 & \\
\hline $\mathrm{CCC}$ & 2 & 27 & 29 & \\
\hline HCC & 1 & 3 & 4 & \\
\hline GB mass/cancer & 2 & 6 & 7 & \\
\hline Other benign liver mass/cystic lesion & 2 & 16 & 19 & \\
\hline Gastroinestinal/Non-gastroinestinal mass or cancer & $10(8.8)$ & $133(16.8)$ & $143(15.7)$ & \\
\hline Gastrointestinal SMT/GIST & 2 & 54 & 56 & \\
\hline Gastroinestinal mass/cancer & 1 & 11 & 12 & \\
\hline Intra-abdominal mass/cancer & 5 & 40 & 45 & \\
\hline Intra-abdominal GIST/NET & 2 & 11 & 13 & \\
\hline Spleen/adrenal gland/lung mass & - & 17 & 17 & \\
\hline LN & $20(17.5)$ & $144(18.5)$ & $164(18.1)$ & \\
\hline LN metastasis & 10 & 74 & 84 & \\
\hline Other LN disease & 7 & 47 & 54 & \\
\hline Lymphoma & 3 & 23 & 26 & \\
\hline Pancreas site & $72(63.2)$ & $444(55.9)$ & $516(56.8)$ & 0.145 \\
\hline Head and neck & 26 & 167 & 193 & \\
\hline Body & 33 & 168 & 201 & \\
\hline Tail & 10 & 86 & 96 & \\
\hline Multiple sites & 3 & 23 & 26 & \\
\hline Non pancreas site & $42(36.8)$ & $350(44.1)$ & $392(43.1)$ & \\
\hline Maximal diameter $($ Mean \pm SD) $(\mathrm{mm})$ & $28.52 \pm 17.43$ & $28.12 \pm 22.92$ & & 0.860 \\
\hline$\leq 20 \mathrm{~mm}$ & $45(39.5)$ & $316(39.8)$ & 361 & \\
\hline$>20 \mathrm{~mm}$ & $69(60.5)$ & $478(60.2)$ & 547 & \\
\hline Puncture route & & & & 0.147 \\
\hline Stomach & $64(7)$ & $504(55.5)$ & $568(62.6)$ & \\
\hline Duodenum & $36(4)$ & $185(20.4)$ & $221(24.3)$ & \\
\hline Esophagus & $7(0.8)$ & $64(7.0)$ & $71(7.8)$ & \\
\hline Other & $7(0.8)$ & $41(4.5)$ & $48(5.3)$ & \\
\hline
\end{tabular}


- Table2 (Continuation)

\begin{tabular}{|c|c|c|c|c|}
\hline & $\begin{array}{l}\text { ATD group } \\
n=114(\%)\end{array}$ & $\begin{array}{l}\text { Non ATD group } \\
n=794(\%)\end{array}$ & $\begin{array}{l}\text { Total } \\
n=908\end{array}$ & $P$ value \\
\hline Cystic lesion & $15(13.2)$ & $81(10.2)$ & $96(10.5)$ & 0.337 \\
\hline Micro-cyst & 0 & 11 & 11 & \\
\hline Macro-cyst & 10 & 54 & 64 & \\
\hline Cystic- necrosis/degeneration/retention & 5 & 16 & 21 & \\
\hline No cystic lesion & $99(86.8)$ & $713(89.8)$ & $812(89.4)$ & \\
\hline \multicolumn{5}{|l|}{ Ascites } \\
\hline No & $106(11.7)$ & $770(84.8)$ & 876 & 0.082 \\
\hline Small & $6(5.3)$ & $16(2)$ & 22 & \\
\hline Moderate & $2(1)$ & $8(1)$ & 10 & \\
\hline \multicolumn{5}{|l|}{ Needle size } \\
\hline $19 G$ & 8 & 58 & $66(7.2)$ & 0.554 \\
\hline $20 G$ & 2 & 19 & $21(2.4)$ & \\
\hline $22 \mathrm{G}$ & 93 & 668 & $761(83.8)$ & \\
\hline $25 G$ & 11 & 49 & $60(6.6)$ & \\
\hline Number of needle passes (Mean \pm SD) & $2.90 \pm 1.30$ & $2.77 \pm 1.24$ & & 0.453 \\
\hline$\leq 2$ & $51(44.7)$ & $385(48.5)$ & 436 & \\
\hline$>2$ & $63(55.3)$ & $409(51.5)$ & 472 & \\
\hline $\begin{array}{l}\text { Suction } \\
\text { Yes }\end{array}$ & $107(11.8)$ & $712(78.4)$ & 819 & 0.180 \\
\hline No & $7(0.8)$ & $82(9.0)$ & 89 & \\
\hline \multicolumn{5}{|l|}{ Hypervascular lesion } \\
\hline Yes & $6(0.7)$ & $83(11.9)$ & 89 & 0.092 \\
\hline No & $108(9.1)$ & $711(78.3)$ & 819 & \\
\hline
\end{tabular}

rombotic group $(0.9 \%)$ was on thienopyridine due to concurrent diabetes mellitus, hypertension, and cerebral vascular disease and switched to ASA before EUS-FNA for pancreatic cancer. This patients restarted thienopyridine 1 day after the procedure. Four days after the procedure, the patient developed left hemiparesis and brain magnetic resonance imaging showed acute right middle cerebral infarction. The patient received palliative care for 2 weeks before returning to their original hospital. The patient with hypotension was in the anticoagulant group and was normotensive during the procedure. However, within 24 hours, the blood pressure had dropped to $80 / 50 \mathrm{~mm} \mathrm{Hg}$ and pulse rate to 70 to $88 / \mathrm{min}$ without an apparent cardiac cause or blood loss. The patient's symptoms resolved after appropriate hydration. The patient with acute pancreatitis developed typical abdominal pain with an amylase level three times the upper normal limit and CT showed diffuse pancreatic swelling, leading to a prolonged hospital stay of 4 to 10 days.

In addition, postoperative fever developed in 11 patients, two in the antithrombotic and nine in the non-antithrombotic group $(P=0.571)$. The patients with significant bleeding had diagnoses of pancreatic duct carcinoma (3 cases), PNET (2 cases), and lymphoma (1 case).

Factors associated with bleeding were analyzed ( $\downarrow$ Table 5). Only antithrombotic use $(P=0.003)$ and INR $(P=0.007)$ were significantly higher in patients who experienced bleeding. No bleeding events occurred in patients who were punctured with $20 \mathrm{G}$ and $25 \mathrm{G}$ needles. Length of hospital stays was significantly longer in the significant bleeding group (13.1 days) than the non-bleeding group (4.4 days; $P=0.003$ ). Subgroup analysis of all bleeding cases is shown in $>$ Table 6. 
Table 3 Significant bleeding events according to antithrombotic management.

\begin{tabular}{|c|c|c|c|c|c|}
\hline \multirow[t]{2}{*}{ ATD management } & \multicolumn{2}{|c|}{ Bleeding case } & \multirow[t]{2}{*}{ Total } & \multirow[t]{2}{*}{ \% Bleed/group } & \multirow[t]{2}{*}{$P$ value } \\
\hline & Yes & No & & & \\
\hline Antithrombotic group & 4 & 110 & 114 & $(3.4 \%, 4 / 114)$ & 0.601 \\
\hline 1. Continue & 2 & 61 & 63 & $(3.2 \%, 2 / 63)$ & \\
\hline - ASA,cilostazol,other antiplatelet & 2 & 61 & 63 & & \\
\hline 2. Discontinue & 1 & 40 & 41 & $(2.43 \%, 1 / 41)$ & \\
\hline - Switched to ASA ${ }^{1}$ & 0 & 14 & 14 & & \\
\hline - Continued ASA ${ }^{1}$ & 1 & 10 & 11 & & \\
\hline - Other & 0 & 16 & 16 & & \\
\hline 3. Heparin replacement & 1 & 9 & 10 & $(10 \%, 1 / 10)$ & \\
\hline Non-Antithrombotic group & 2 & 792 & 794 & $(0.2 \%, 2 / 794)$ & \\
\hline Total & 6 & 902 & 908 & $(0.7 \%, 6 / 908)$ & \\
\hline
\end{tabular}

- Table 4 Bleeding events and other adverse events.

\begin{tabular}{|c|c|c|c|c|c|c|c|c|}
\hline \multirow[t]{2}{*}{ Complication of EUS-FNA } & \multirow{2}{*}{$\begin{array}{l}\text { ATD } \\
n=114 \text { (\%) }\end{array}$} & \multirow{2}{*}{$\begin{array}{l}\text { Non-ATD } \\
n=794 \text { (\%) }\end{array}$} & \multirow{2}{*}{$\begin{array}{l}\text { Total } \\
n=908\end{array}$} & \multirow{2}{*}{$\begin{array}{l}\text { Severity } \\
\text { (ASGE) }\end{array}$} & \multicolumn{2}{|c|}{ Univariate analysis } & \multicolumn{2}{|c|}{ Multivariate analysis } \\
\hline & & & & & OR(95\%Cl) & $P$ value $^{2}$ & OR(95\%CI) & $P$ value $^{2}$ \\
\hline $\begin{array}{l}\text { Significant bleeding } \\
(\mathrm{Hb} \text { drop }>2 \mathrm{~g} / \mathrm{dL})\end{array}$ & $4(0.4)$ & $2(0.2)$ & $6(0.7)$ & $\begin{array}{l}\text { Mild }=5 \\
\text { Mod }=1\end{array}$ & $\begin{array}{l}9.59 \\
(2.12-43.1)\end{array}$ & $0.006^{1}$ & $\begin{array}{l}14.4 \\
(2.6-79.54)\end{array}$ & $0.002^{1}$ \\
\hline $\begin{array}{l}\text { Non-significant bleeding } \\
\text { (Hb drop } \leq 2 \mathrm{~g} / \mathrm{dL} \text { ) }\end{array}$ & - & $5(0.6)$ & $5(0.6)$ & Mild $=5$ & $\begin{array}{l}1.14 \\
(1.11-1.17)\end{array}$ & 1.000 & - & 0.997 \\
\hline Total bleeding & $4(0.4)$ & $7(0.8)$ & $11(1.2)$ & $\begin{array}{l}\text { Mild }=10 \\
\text { Mod }=2\end{array}$ & $\begin{array}{l}4.08 \\
(1.17-14.19)\end{array}$ & $0.039^{1}$ & $\begin{array}{l}0.24 \\
(0.07-0.85)\end{array}$ & $0.027^{1}$ \\
\hline Cerebral infarction & $1(0.9)$ & - & $1(0.1)$ & Severe $^{1}$ & - & 0.126 & - & - \\
\hline Hypotension & $1(0.9)$ & - & $1(0.1)$ & Mild & - & 0.126 & - & - \\
\hline Fever & $2(0.2)$ & $9(1)$ & $11(1.2)$ & Mild & $\begin{array}{l}1.56 \\
(0.33-7.30)\end{array}$ & 0.638 & - & 0.571 \\
\hline Acute pancreatitis & - & $1(0.1)$ & $1(0.1)$ & Mod & - & 0.100 & - & - \\
\hline \multicolumn{9}{|c|}{$\begin{array}{l}\text { ATD, antithrombotic drugs; EUS-FNA endoscopic-guided fine-needle aspiration; Hb, hemoglobin; ASGE, American Society of Gastrointestinal Endoscopy; OR, odds } \\
\text { ratio; Cl, confidence interval; Mod, moderate }\end{array}$} \\
\hline
\end{tabular}

\section{Discussion}

A previous large systematic review of 22 studies had suggested that risk of bleeding associated with gastrointestinal procedures in patients receiving antiplatelet therapy was not significantly higher than in patients with interrupted antiplatelet therapy or in those with no bleeding at all. Only five studies showed a higher risk of bleeding during continuous antiplatelet therapy and there was only one prospective study of 241 EUSFNA and/or TCB procedures that found bleeding in 0/26 of the ASA/NSAIDs group, 2/6 of the LMWH group, and 7/190 in the control group with no statistically significant difference $(P=$
0.023). In addition, the mean number of FNA passes, applications of suction, blood specimens, and cellular yield were not significantly different. EUS-FNA or TCB is safe in patients taking ASA or NSAIDs [16].

In addition, bleeding risk was found to be increased according to specific types of antithrombotic drugs, such as warfarin and heparin. A recent meta-analysis showed that periprocedural bridging therapy with heparin increased overall risk of major bleeding without a significant decrease in risk of thromboembolic events $[16,17]$.

A previous study from Japan on EUS-FNA for solid lesions in patients on antithrombotic therapy found that the overall 
- Table 5 Analysis of factors associated with bleeding.

\begin{tabular}{|c|c|c|c|c|}
\hline Factors & $\begin{array}{l}\text { Bleed (\%) } \\
n=6\end{array}$ & $\begin{array}{l}\text { No bleed }(\%) \\
n=902\end{array}$ & $P$ value $^{2}$ & OR(95\%Cl) \\
\hline Age, mean $\pm S D$ & $65.71 \pm 7.41$ & $64.63 \pm 11.43$ & 0.909 & \\
\hline$\geq 60 Y$ & $6(0.7)$ & $642(70.7)$ & 0.680 & $\begin{array}{l}2.42 \\
(0.29-20-20)\end{array}$ \\
\hline$<60 Y$ & $1(0.1)$ & $259(28.5)$ & & \\
\hline $\begin{array}{l}\text { Sex } \\
\text { Male }\end{array}$ & $2(0.2)$ & $513(56.5)$ & 0.412 & $0.38(0.06-2.08)$ \\
\hline Female & $4(0.4)$ & $389(42.8)$ & & \\
\hline ATD group & $4(0.4)$ & $110(12.1)$ & $0.003^{1}$ & $\begin{array}{l}14.4 \\
(2.60-79.54)\end{array}$ \\
\hline Non-ATD & $2(0.2)$ & $792(87.2)$ & & \\
\hline $\mathrm{Hb}(\mathrm{g} / \mathrm{dl})$ & $13.26 \pm 1.86$ & $13.06 \pm 1.74$ & 0.779 & \\
\hline $\mathrm{WBC}(/ \mathrm{mm} 3)$ & $7710 \pm 2383$ & $6873 \pm 2683$ & 0.446 & \\
\hline Platelets $\left(\times 10^{4} / \mathrm{mm}^{3}\right)$ & $23.15 \pm 6.79$ & $23.55 \pm 11.85$ & 0.934 & \\
\hline INR & $1.15 \pm 0.152$ & $1.05 \pm 0.091$ & $0.007^{1}$ & \\
\hline \multicolumn{5}{|l|}{ Organ of puncture } \\
\hline Pancreas & $5(0.6)$ & $511(56.3)$ & 0.705 & $1.90(0.37-9.89)$ \\
\hline Non pancreas & $2(0.2)$ & $390(43.0)$ & & \\
\hline \multicolumn{5}{|l|}{ Route of puncture } \\
\hline Stomach & $5(0.6)$ & $563(62)$ & 0.419 & $\begin{array}{l}3.01 \\
(0.35-25.87)\end{array}$ \\
\hline Other & $1(0.1)$ & $339(37.3)$ & & \\
\hline \multicolumn{5}{|c|}{ Maximal diameter, mean \pm SD $(\mathrm{mm})$} \\
\hline$\leq 20 \mathrm{~mm}$ & $2(0.2)$ & $359(39.5)$ & 1.000 & $0.75(0.14-4.15)$ \\
\hline$>20 \mathrm{~mm}$ & $4(0.4)$ & $542(59.8)$ & & \\
\hline \multicolumn{5}{|l|}{ Cystic lesion } \\
\hline Yes & $2(0.2)$ & $86(9.5)$ & 0.108 & $\begin{array}{l}0.108 \\
(0.03-1.16)\end{array}$ \\
\hline No & $4(0.4)$ & $816(89.9)$ & & \\
\hline \multicolumn{5}{|l|}{ Ascites } \\
\hline No & $6(0.7)$ & $870(95.8)$ & 1.000 & $1.02-1.05$ \\
\hline Mild & 0 & $22(2.4)$ & & \\
\hline Moderate & 0 & $10(1.1)$ & & \\
\hline \multicolumn{5}{|l|}{ Number of passes } \\
\hline$\leq 2$ & $3(0.3)$ & $433(47.7)$ & 1.000 & $\begin{array}{l}1.08 \\
(0.217-3.395)\end{array}$ \\
\hline$>2$ & $3(0.3)$ & $469(51.7)$ & & \\
\hline \multicolumn{5}{|l|}{ Needle size } \\
\hline $22 \mathrm{G}$ & $5(0.6)$ & $756(83.3)$ & 1.000 & $0.96(0.11-8.32)$ \\
\hline $19 G$ & $1(0.1)$ & $65(7.2)$ & & \\
\hline $20 G$ & 0 & $21(2.3)$ & & \\
\hline $25 G$ & 0 & $60(6.6)$ & & \\
\hline
\end{tabular}


- Table 5 (Continuation)

\begin{tabular}{|c|c|c|c|c|}
\hline Factors & $\begin{array}{l}\text { Bleed (\%) } \\
n=6\end{array}$ & $\begin{array}{l}\text { No bleed (\%) } \\
n=902\end{array}$ & $P$ value $^{2}$ & OR(95\%Cl) \\
\hline No. lesion punctures, mean \pm SD & $1.15 \pm 0.83$ & $1.19 \pm 0.51$ & 0.956 & \\
\hline$<2$ & $4(0.4)$ & $769(84.7)$ & 0.220 & $0.34(0.63-1.90)$ \\
\hline$\geq 2$ & $2(0.2)$ & $133(14.6)$ & & \\
\hline \multicolumn{5}{|l|}{ Suction technique } \\
\hline Yes & $4(0.4)$ & $827(91.1)$ & 0.085 & $\begin{array}{l}0.085 \\
(0.033-1.007)\end{array}$ \\
\hline No & $2(0.2)$ & $75(8.3)$ & & \\
\hline \multicolumn{5}{|l|}{ Hyper-vascular tumor ${ }^{1}$} \\
\hline Yes & $2(0.2)$ & $815(89.6)$ & 0.110 & $\begin{array}{l}4.68 \\
(0.85-25.94)\end{array}$ \\
\hline No & $4(0.6)$ & $87(9.6)$ & & \\
\hline Length of hospital stay & $13.17 \pm 22.49$ & $4.40 \pm 6.88$ & $0.003^{1}$ & $3.08-14.45$ \\
\hline \multicolumn{5}{|c|}{$\begin{array}{l}\text { OR, odds ratio; } \mathrm{Cl} \text {, confidence interval; SD, standard deviation; ATD, antithrombotic drug; } \mathrm{HB} \text {, hemoglobin; WBC, white blood cells; INR, international norr } \\
\text { ratio } \\
1{ }^{1} \text { Hypervascular tumor included hepatocellular carcinoma, neuroendocrine tumors, gastrointestinal stromal tumors and carcinoid tumor } \\
{ }^{2} \text { Statistically significant }(P<0.05)\end{array}$} \\
\hline
\end{tabular}

bleeding event rate was $0.9 \%$ and that all bleeding events were intraoperative. Subgroup analysis according to antithrombotic agent revealed bleeding event rates of $1.0 \%(6 / 611), 0 \%(0 /$ $62), 1.6 \%(1 / 61)$, and $0 \%(0 / 8)$ in non-administration, discontinuation, continuation of ASA or cilostazol, and heparin replacement groups, respectively [6]. The antithrombotic therapy group had only one case of intraoperative bleeding in the continuous group, and bleeding risk was not related to the type or size of the lesion, needle size, needle pass route, the number of passes, or the type of antithrombotic therapy.

In this study the overall significant bleeding rate was $0.7 \%$, $0.4 \%$ in the antithrombotic group and $0.2 \%$ in the non-antithrombotic group.According to subgroup classification using the updated JGES guidelines, significant bleeding in the antithrombotic group occurred in two cases, one case and one case of the continuation, discontinuation, and heparin replacement groups, respectively and two cases in the non-antithrombotic group. All bleeding in the antithrombotic group occurred postoperatively (within 1-14 days).Bleeding risk from antithrombotics was significantly higher $(P=0.003)$. Our results differ from the outcomes of a previous study [6] in that postoperative significant bleeding occurred in four cases in the antithrombotic group and two cases in the non-antithhrombotic group. One prospective study of EUS-FNA or Trucut biopsy in EUS-FNA reported one case of immediate bleeding and one case of late bleeding from six cases (33.3\%) in a heparin/LMWH group but no bleeding in continued ASA or NSAID group [5]. Another retrospective study of endoscopic submucosal dissection reported a delayed bleeding rate in patients taking antithrombotic drugs of $11.6 \%(P=0.013)$ [18]. Continuation of antithrombotics in EUS-FNA may present a risk of operative or delayed bleeding and care should be taken after the procedure.
The non-significant bleeding rate was $0.6 \%$ and the total bleeding event rate was $1.2 \%$, all of which were found in the non-antithrombotic group. There were no incidences of severe bleeding in our study. Both significant and total bleeding events were more common in the antithrombotic group. We found that patients in the antithrombotic group in this study were older, more commonly male, and had higher rates of comorbidity and lower hemoglobin levels at baseline than those in the non-antithrombotic group. In addition, one patient who was on ASA and discontinuation of thienopyridine developed cerebral infarction. This patient had a high thromboembolism risk and restarted thienopyridine 1 day after the procedure.

There are concerns about postprocedural follow-up and length of hospital stay in patients who experience bleeding after medication adjustment, especially when switching from warfarin to heparin, and the need for close observation in these cases. However, after 1 month of follow-up, we recorded no instances of late death and only one case of major morbidity (the aforementioned cerebral infarction. Factors such as maximal diameter of the lesion, puncture route, number of EUS passes, suction technique, cystic nature, presence of ascites, and lesion vascularity were not associated with bleeding risk.

The major limitation of this study was the low number of patients in the antithrombotic group, especially the anticoagulant subgroup. In the future, larger prospective studies of patients with high-risk factors such as antithrombotic therapy, especially those taking thienopyridines or anticoagulants and those with hypervascular masses, are needed. 


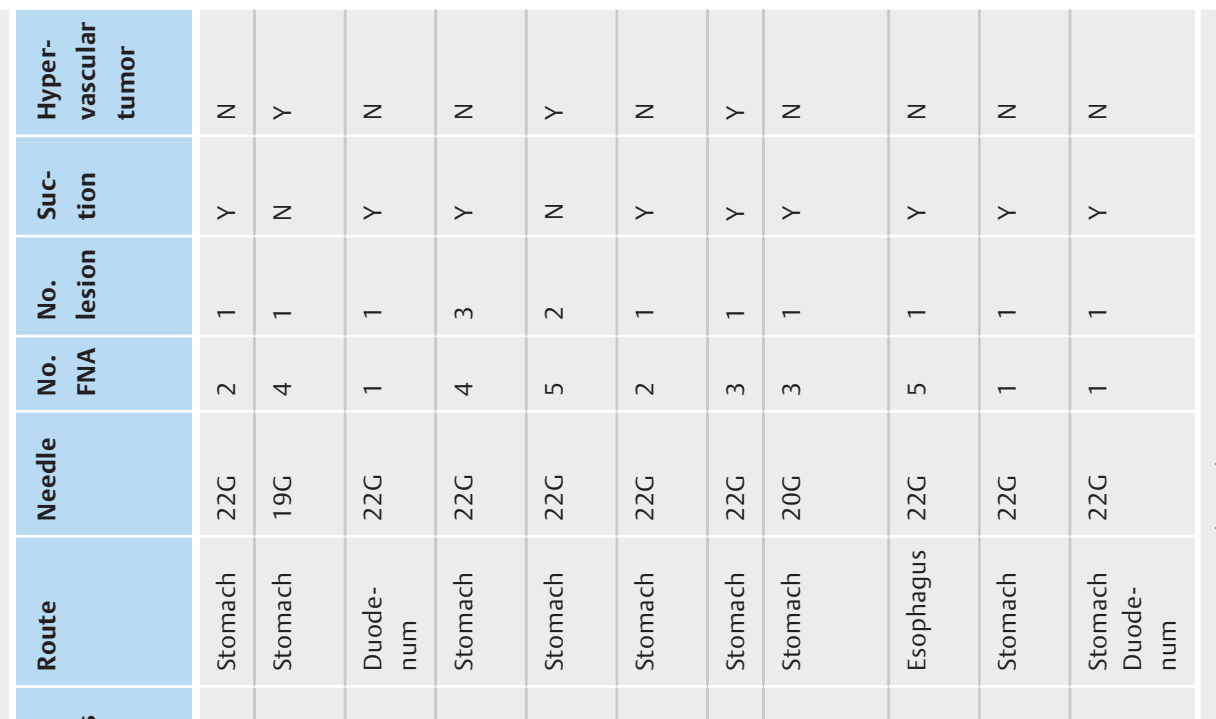

\begin{tabular}{|c|c|c|c|c|c|c|c|c|c|c|c|}
\hline$\dot{x}$ & $z$ & $z$ & $z$ & z & z & z & $z$ & $z$ & z & $z$ & $>$ \\
\hline
\end{tabular}

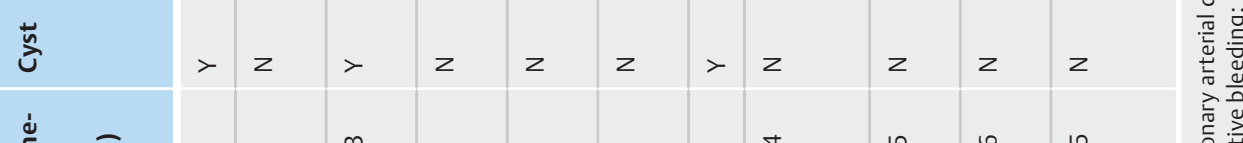

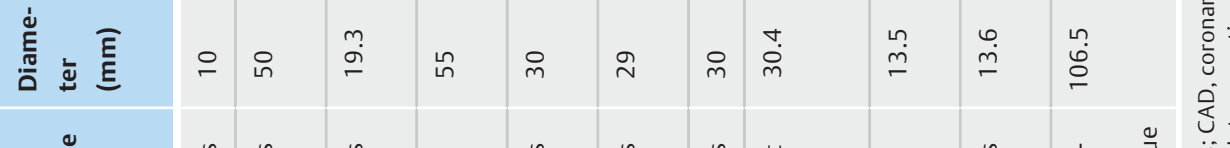

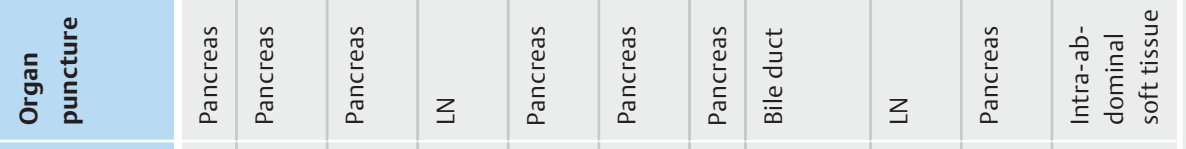

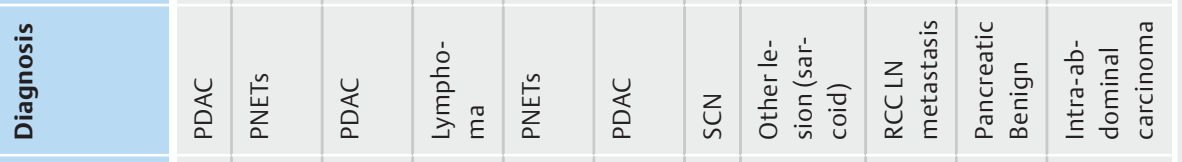

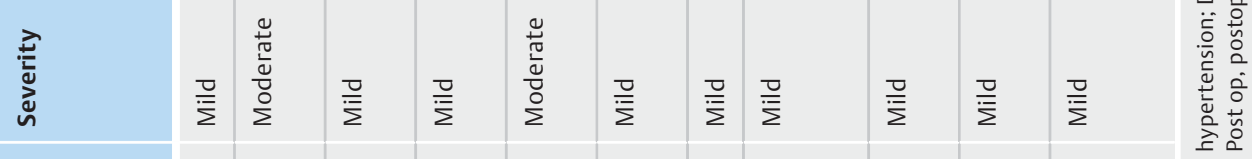

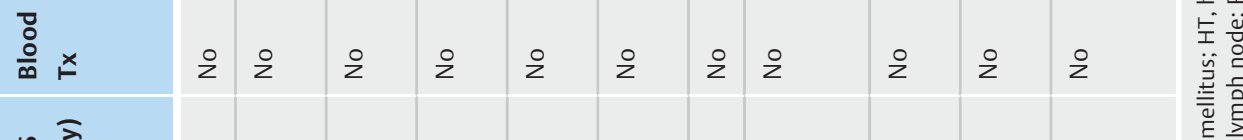

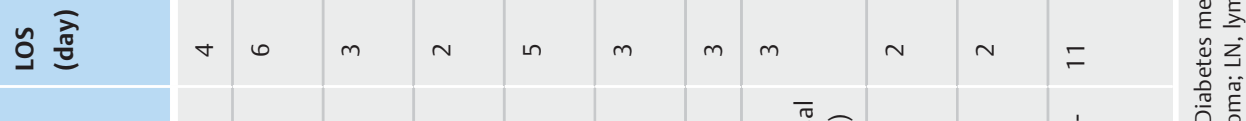

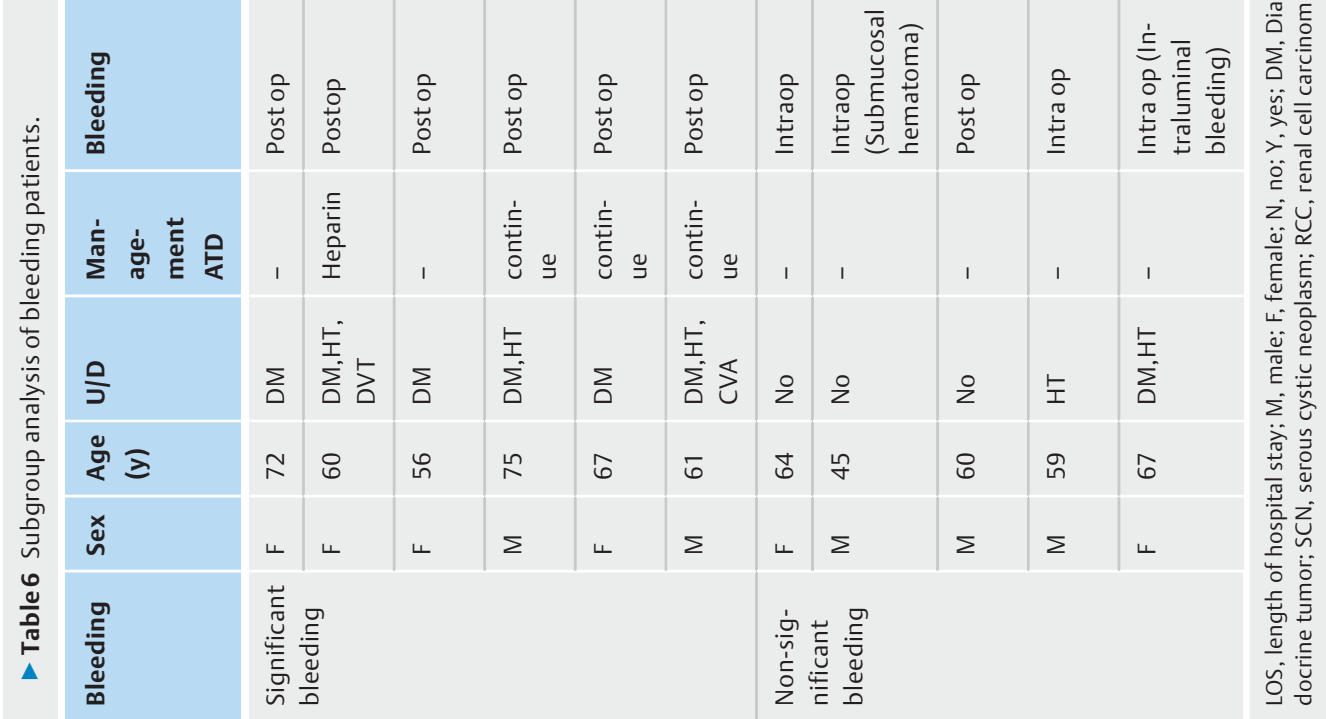




\section{Conclusion}

The bleeding risk in the antithrombotic group was higher than in the non-antithrombotic group. However, no severe bleeding was found in patients who continued or discontinued antithrombotic therapy and only one thromboembolic event occurred. Relative risks of bleeding and thrombosis should be carefully assessed during the preprocedural decision-making process.

\section{Acknowledgements}

The authors would like to thank the staff residents and statisticians of the Department of Gastroenterology of Aichi Cancer Center Hospital and Bhumibol Adulyadej Hospital for their assistance in performing this study.

\section{Competing interests}

None

\section{Reference}

[1] Hamada T, Yasunaga H, Nakai Y et al. Severe bleeding and perforation are rare complications of endoscopic ultrasound-guided fine needle aspiration for pancreatic masses: an analysis of 3,090 patients from 212 hospitals. Gut Liver 2014; 8: 215-218

[2] Wang KX, Ben QW, Jin ZD et al. Assessment of morbidity and mortality associated with EUS-guided FNA: a systematic review. Gastrointest Endosc 2011; 73: 283-290

[3] Varadarajulu S, Eloubeidi MA. Frequency and significance of acute intracystic hemorrhage during EUS-FNA of cystic lesions of the pancreas. Gastrointest Endosc 2004; 60: 631-635

[4] Oprea AD, Noto C], Halaszynski TM. Risk stratification, perioperative and periprocedural management of the patient receiving anticoagulant therapy. J Clin Anesth 2016; 34: 586 - 599

[5] Kien-Fong VuC, Chang F, Doig L et al. A prospective control study of the safety and cellular yield of EUS-guided FNA or Trucut biopsy in patients taking aspirin, nonsteroidal anti-inflammatory drugs, or prophylactic low molecular weight heparin. Gastrointest Endosc 2006; 63: 808-813
[6] Inoue T, Okumura F, Sano $\mathrm{H}$ et al. Bleeding risk of endoscopic ultrasound-guided fine-needle aspiration in patients undergoing antithrombotic therapy. Dig Endosc 2016: doi:10.1111/den.12687

[7] Burger W, Chemnitius JM, Kneissl GD et al. Low-dose aspirin for secondary cardiovascular prevention - cardiovascular risks after its perioperative withdrawal versus bleeding risks with its continuation - review and meta-analysis. J Intern Med 2005; 257: 399-414

[8] Boustière C, Veitch A, Vanbiervliet G et al. Endoscopy and antiplatelet agents. European Society of Gastrointestinal Endoscopy (ESGE) Guideline. Endoscopy 2011; 43: 445-461

[9] Committee ASoP. Anderson MA, Ben-Menachem T et al. Management of antithrombotic agents for endoscopic procedures. Gastrointest Endosc 2009; 70: 1060 - 1070

[10] Veitch AM, Baglin TP, Gershlick AH et al. Guidelines for the management of anticoagulant and antiplatelet therapy in patients undergoing endoscopic procedures. Gut 2008; 57: 1322

[11] Fujimoto K, Fujishiro M, Katou M et al. Guidelines for gastroenterological endoscopy in patients undergoing antithrombotic treatment. Gastroenterol Endosc 2012; 54: 2075-2102 (in Japanese)

[12] Fujimoto K, Fujishiro M, Kato M et al. Guidelines for gastroenterological endoscopy in patients undergoing antithrombotic treatment. Dig Endosc 2014; 26: 1 - 14

[13] Matsumura T, Arai M, Maruoka D et al. Risk factors for early and delayed post-operative bleeding after endoscopic submucosal dissection of gastric neoplasms, including patients with continued use of antithrombotic agents. BMC Gastroenterology 2014; 14: 172

[14] Cotton PB, Eisen GM, Aabakken L et al. A lexicon for endoscopic adverse events: report of an ASGE workshop. Gastrointest Endosc 2010; 71: $446-454$

[15] Affi A, Vazquez-Sequeiros E, Norton ID et al. Acute extraluminal hemorrhage associated with EUS-guided fine needle aspiration: Frequency and clinical significance. Gastrointestinal Endoscopy 2001; 53: $221-225$

[16] Baron TH, Kamath PS, McBane RD. Management of antithrombotic therapy in patients undergoing invasive procedures. N Engl J Med 2013; 368: 2113-2124

[17] Kowalewski M, Suwalski P, Raffa GM et al. Meta-analysis of uninterrupted as compared to interrupted oral anticoagulation with or without bridging in patients undergoing coronary angiography with or without percutaneous coronary intervention. Int J Cardiol 2016; 223: $186-194$

[18] Koh R, Hirasawa K, Yahara S et al. Antithrombotic drugs are risk factors for delayed postoperative bleeding after endoscopic submucosal dissection for gastric neoplasms. Gastrointest Endosc 2013; 78: 476 483 